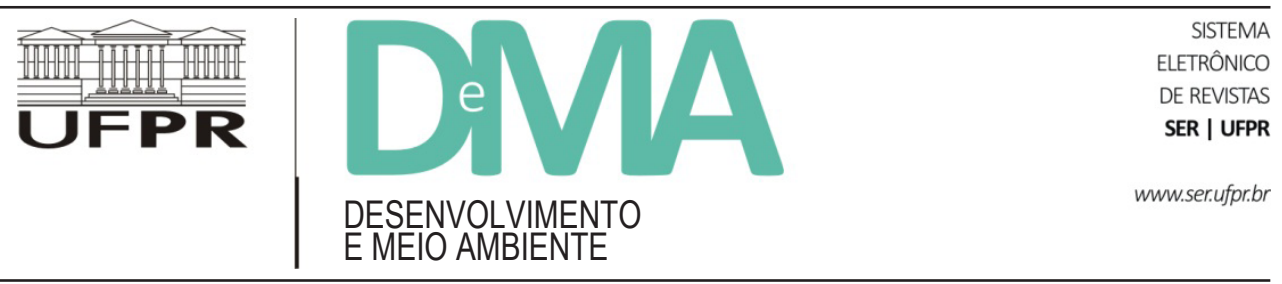

\title{
Depoimento de Maria de Nazareth Baudel Wanderley ${ }^{1}$
}

Meus queridos

Fui convidada para compartilhar da homenagem que o MADE agora promove a Magda Zanoni, em referência ao seu falecimento em março desse ano. Por razões pessoais, não tenho condições de comparecer a esse evento e abraçar todos vocês, irmanados nesse profundo sentimento de perda. Mas, para não ficar totalmente ausente, envio essa mensagem, que Angela Ferreira lerá.

Para mim, como, certamente, para muitos de vocês, ainda é muito difícil falar da morte de Magda, não imaginá-la mais entre nós, a vivência desse luto nos deixando tristes e silenciosos.

Guardarei na memória e no coração a lembrança dessa mulher, sempre coerente com os seus princípios, com uma impressionante capacidade de trabalho e com um dom inesgotável para mobilizar pessoas e instituições em função das causas sociais que a mobilizaram - a ela mesma - desde a sua juventude.
No meio acadêmico, encontramos com muita frequência mulheres com essa têmpera, algumas delas presentes nessa assembleia. Mas, tenho a certeza que, os que a conheceram de perto, concordarão comigo: nesse campo, Magda ganhava o primeiro lugar.

Coerência e dom de si, inclusive em momentos particularmente difíceis da história da sociedade brasileira, mas também da sociedade francesa, à qual ela, com justa razão, se sentia pertencente.

Era firme, uma lutadora, mas não era durona. Como amiga pessoal dela, posso dizer: Magda era extremamente afetuosa, "derretida", mesmo. Sempre que nos encontrava, nos trazia presentes de Paris, queria saber de nossas vidas, curtia nossas boas notícias, inclusive a minha filha Marina, que também ganhava presentinhos parisienses. Nós retribuíamos com peças do artesanato pernambucano. Era discretamente vaidosa. Nunca a vi sem o brilho de um batonzinho e de sombra nos olhos. Afinal, beleza é fundamental.

\footnotetext{
${ }^{1}$ Doutora em Sociologia pela Universidade de Paris X - Nanterre, França. Foi professora de Sociologia Rural da Unicamp e da UFPE e coordenadora do Laboratório de Estudos Rurais do Nordeste - LAE-Rural. É sócia fundadora da Rede de Estudos Rurais, da qual foi presidente. Em 2011, recebeu o prêmio Florestan Fernandes, concedido pela Sociedade Brasileira de Sociologia.
} 
Eu a conheci em 1970, em Paris, num contexto, por sinal, bem especial. Era a copa do mundo e os estudantes brasileiros iam à Casa do Brasil, na Cidade Universitária, para assistir os jogos. Magda morava nessa casa. No último jogo, quando o Brasil se sagrou tricampeão, a felicidade explodiu em todos nós, que queríamos comemorar com um carnaval. Magda e seus amigos não admitiam que se pudesse comemorar algo que lhes parecia associado à ditadura que dominava o nosso país e apagaram todas as luzes da Casa do Brasil. Festa frustrada, carnaval adiado, mas amizade conquistada desde então.

Cada um de vocês tem, certamente, uma história para contar a respeito de Magda. É o lastro da amizade e da admiração, que sobrevive ao seu passamento. Conversaremos sobre isso, cada vez que nos encontrarmos.

Mas, quero completar essa mensagem, oferecendo o meu testemunho sobre sua presença atuante na sociedade. Nos últimos anos, tive a honra e o privilégio de compartilhar com Magda, juntamente com uma grande equipe, a realização de uma pesquisa sobre o Programa Territórios da Cidadania, implementado sob a coordenação do MDA. Posso testemunhar o quanto era verdadeira, radical e coerente essa sua presença.

Pesquisadora, formadora, animadora, mobilizadora, assim era a multifacetária militância de Magda, sempre capaz de afirmar os pontos de convergência entre a construção da ciência e a prática política; a sociedade e a natureza; a disciplina e a interdisciplinaridade; a universidade e a comunidade; a sala de aula e a pesquisa de campo; o Brasil e a
França. Magda levava, quando julgava necessário, militantes do MST para as reuniões do CNTBIO; acompanhava jovens estudantes franceses e brasileiros nos primeiros contatos com o mundo rural; descolava, como só ela, recursos institucionais para pesquisas e para a realização de eventos, aparentemente de difícil acesso. Cobrava dos técnicos o compromisso com as demandas da sociedade e de todos nós a coerência com a ciência cidadã.

Nessa costura, ela fazia emergir, não uma perspectiva binária, de polarização ou oposição, mas um vasto campo de inserção, que ultrapassava de longe o recorte fechado do "mundo acadêmico". É dela, juntamente com Claude Raynaud, a seguinte reflexão sobre o recém criado Doutorado sobre Meio Ambiente e Desenvolvimento - MADE - na UFPR, "coroamento de vários anos de trabalho realizado em múltiplas frentes":

- a de uma reflexão teórica referente às relações entre natureza e sociedades, entre meio ambiente e desenvolvimento, entre ciência e prática;

- de uma confrontação metodológica em torno do tema da interdisciplinaridade e de sua prática no campo da formação e da pesquisa;

- enfim, a de uma luta contra os estrangulamentos institucionais e sociais que se manifestam assim que novos procedimentos e condutas passam a modificar os hábitos intelectuais e os poderes estabelecidos ${ }^{1}$.

Permito-me, mesmo que sinteticamente, dada a natureza da minha intervenção, privilegiar em sua trajetória três temáticas de pesquisa e dois princípios norteadores de sua militância,

${ }^{1}$ Prefácio ao primeiro número dos Cadernos de Desenvolvimento e Meio Ambiente, publicado em 1994 e reeditado pela revista Desenvolvimento e Meio Ambiente, vol. 33, abril 2015, p. 2. 
todos intrínseca e coerentemente articulados. No primeiro caso - das temáticas - refiro-me à agricultura camponesa, à ruralidade contemporânea e às questões ambientais. Para refletir sobre elas, aproprio-me, aqui, de seus próprios textos, muitos escritos em parceria.

\section{Por uma outra agricultura:}

Apontando para a polarização das formas sociais de produção agrícola, existente no mundo rural brasileiro, Magda Zanoni e Angela Ferreira formulam uma questão central a nortear nossas pesquisas sobre o tema:

Diante dos efeitos do modelo latifúndio/ grande empresa em termos de exclusão social e pauperização, tanto rural como urbana, em que medida é pertinente, tanto do ponto de vista teórico, como em termos de políticas públicas, pensar em alternativas para construir outra agricultura, que consolide os segmentos menos capitalizados da agricultura familiar e os assentamentos rurais? Essa questão não pressupõe a ideia de que se pode substituir hegemonias num setor da sociedade - o rural, o agrário - mas traz implícita a virtualidade de mudanças que pode tornar plural o quadro de alternativas existentes de desenvolvimento rural e agrícola ${ }^{2}$.

É essa outra agricultura que a obra de Magda contribuiu para conhecer, reconhecer e consolidar o seu espaço de reprodução.

\section{A ruralidade contemporânea:}

No mesmo texto, que acabo de citar, encontro, numa frase lapidar, a concepção que ela propõe sobre a ruralidade:
[...] antes, tratava-se de pensar as condições de levar ao campo tradicional as inovações tecnológicas e outras subjacentes à vida moderna; agora, é a questão do desenvolvimento sustentável que reveste este debate. Isso significa repensar o rural como espaço de outras agriculturas e também como espaço de vida. De trabalho e de lazer não necessariamente restrito aos agricultores. Significa também repensar a relação deste rural de pluriatividades, mas ainda basicamente agrícola, com as pequenas cidades, ou seja, com o conjunto das dinâmicas do território local (p. 21).

Ressalte-se aqui as consequências das escolhas do pesquisador: observar o mundo rural, considerando-o apenas como um lugar de investimento (do capital ou da concentração da terra) resulta na constatação de um espaço socialmente vazio. É apenas quando o consideramos como um espaço de vida e de trabalho, que conseguimos apreender as comunidades humanas que o povoam e lhe atribuem vitalidade.

\section{A questão ambiental:}

Descubro uma abordagem teórica de Magda, mais uma vez pedagogicamente formulada como uma questão:

Como as transformações do mundo rural e do espaço rural são influenciadas, ou mesmo induzida, pela nova visão das relações entre as sociedades humanas e o meio natural? [...]. Quais condições sócio-políticas são necessárias para que a agricultura cumpra um novo contrato com a sociedade, não apenas restringindo-se à gestão do espaço rural, mas visando a implantação de um modelo de agricultura sustentável, com exigências referentes à

\footnotetext{
${ }^{2}$ Ferreira, A. D. D.; Zanoni, M. Outra agricultura e a reconstrução da ruralidade. In: Ferreira, A. D. D.; Brandenburg, A. (Orgs.). Para pensar outra agricultura. Curitiba: UFPR, 1998, p. 16.
} 
qualidade da alimentação, à saúde das populações e à preservação da natureza? Ou seja, quais condições são necessárias para uma agricultura que garanta a reprodução social e que assegure as condições de reprodutibilidade dos recursos naturais? ${ }^{3}$

A reflexão que responde a essas questões já me permite introduzir o que anunciei antes a respeito dos princípios norteadores de sua militância. Refiro-me, em particular, à solidariedade internacional do campesinato - que a motivou a promover numerosos eventos de intercâmbio entre camponeses franceses e brasileiros - e a afirmação da ciência cidadã.

Sobre essa última, trata-se da produção de conhecimentos voltados para as mais profundas necessidades da sociedade, tendo como fundamento, o respeito pelos seres vivos. É a afirmação do compromisso da ciência e dos cientistas com a sociedade, para a qual deve retornar seu trabalho, de modo a ampliar e aprofundar o campo das informações necessárias ao conhecimento e ao empoderamento dos indivíduos e grupos que a compõem e da formação de jovens pesquisadores imbuídos desses princípios. Ilustro suas posições com duas passagens de seus escritos:

$[\ldots]$ as novas questões sobre o meio ambiente e o rural enquanto processo de desenvolvimento exigem da pesquisa, dos pesquisadores, das ciências, respostas às demandas sociais e, consequentemente, resultados a mais curto prazo. Diante desse novo desafio, surge a discussão sobre os objetivos e as formas de pesquisa. Elabora-se uma nova significação, a da "pesquisa finalizada", isto é, pesquisa rigorosa, semelhante à pesquisa fundamental, à qual se acrescentam os atributos da pesquisa direcionada, pela necessidade de responder a questões, ou seja, ter finalidade (Zanoni, 2004).

Assim, pensamos que a ilustração do desejo de uma outra agricultura chegou ao nível da produção do conhecimento. Não há mais lugar para uma ciência agronômica única, dirigida para um único setor da população rural. Os pobres do campo também observam suas parcelas, experimentam, tiram conclusões, mas nem sempre têm as condições de validá-las e comunicá-las aos seus pares. A pesquisa, em estações experimentais, possui os meios necessários para estabelecer protocolos, sistematizar resultados e difundi-los. No entanto, não responde à diversidade de condições sociais e ambientais existentes nas unidades de produção da agricultura camponesa e familiar existentes. Estas experiências concebidas nas estações são malfadadas quando são testadas na parcela do agricultor e o sucesso em plantar sementes não adaptadas, ou melhor, não cultivadas em situação ideal, é comprometido. Centenas de experiências poderiam ter a mesma importância e significado se fossem privilegiadas pelos mesmos instrumentos e financiamentos, porém, com os atores partidários de uma produção agrícola mais autônoma e mais econômica ${ }^{4}$.

Muito teria ainda a falar sobre Magda. Volto, no entanto, ao meu sentimento de tristeza e luto. Encontro refúgio nas palavras de Daniel Lima, padre, filósofo, professor e poeta pernambucano, as quais gostaria de compartilhar com vocês todos para encerrar minha mensagem de saudade, com um ar de esperança.

\footnotetext{
${ }^{3}$ Zanoni, M. A questão ambiental e o rural contemporâneo. Desenvolvimento e Meio Ambiente, 10, 109, 2004.

${ }^{4}$ Zanoni, M. Relatório de Cooperação Técnica. Brasília: IICA, 2012. Projeto: BRA/10/001. Disponível em: www.iica.org.br
} 
Saudade é bem positiva coisa. Ela é acumu- realmente, jamais foi nosso, mas simplesmente anelação de vida que se viveu com intensidade de xado a nós. A saudade que quero é a que me finca sentimentos e que, assim, se tornou nosso tempo mais no presente e me empurra mais para diante e pessoal, o tempo interior que se identifica com o que somos, com a nossa própria existência, no que tem de mais peculiarmente nossa. Pode-se ter saudade, pois, sem olhar para trás, porque o que se amou uma vez de verdade vai conosco para sempre, não passa nunca, é parte atual e viva de nosso ser pessoal. Se algo ficou para trás, é que jamais existiu para nós me torna mais livre: uma forma de saudade feita de Esperança, de crença na vida, e que é muito mais futuro que passado 5 . Zanoni.

Recife, outubro 2015.

${ }^{5}$ Lima, D. Ideário humanístico; da teologia ao rol-de-roupa. Recife: CEPE, 2014, p. 47. 